Meta

Journal des traducteurs

Translators' Journal

\title{
Conference Interpreting
}

\section{A Multichannel Communication Phenomenon}

\section{Hildegund Bühler}

Volume 30, numéro 1, mars 1985

Interprétation de conférence

URI : https://id.erudit.org/iderudit/002176ar

DOI : https://doi.org/10.7202/002176ar

Aller au sommaire du numéro

Éditeur(s)

Les Presses de l'Université de Montréal

ISSN

0026-0452 (imprimé)

1492-1421 (numérique)

Découvrir la revue

Citer cet article

Bühler, H. (1985). Conference Interpreting: A Multichannel Communication

Phenomenon. Meta, 30(1), 49-54. https://doi.org/10.7202/002176ar

Ce document est protégé par la loi sur le droit d'auteur. L'utilisation des services d'Érudit (y compris la reproduction) est assujettie à sa politique d'utilisation que vous pouvez consulter en ligne.

https://apropos.erudit.org/fr/usagers/politique-dutilisation/
Cet article est diffusé et préservé par Érudit.

Érudit est un consortium interuniversitaire sans but lucratif composé de l’Université de Montréal, l'Université Laval et l'Université du Québec à Montréal. Il a pour mission la promotion et la valorisation de la recherche. https://www.erudit.org/fr/ 


\title{
CONFERENCE INTERPRETING \\ A MULTICHANNEL COMMUNICATION PHENOMENON
}

\author{
HILDEGUND BÜHLER
}

Conference interpreting is not merely a question of repeating words or phrases in another language, a question of code switching, but rather a question of understanding and making oneself understood, of assuming responsibility for the success of the communication process as a second sender in a communication channel that is interrupted because original sender and receiver use different codes. The task of the interpreter is therefore to convey a message, the message of the original sender in real time without loss of information content (cf. Seleskovitch 1978).

Such messages can be encoded either digitally or analogically, with digital encoding by discrete units corresponding for our purposes to verbal codification (e.g. by means of words), analogic encoding representing a continuous relationship corresponding to nonverbal codification (cf. e.g. by means of actions) (Kendon 1981: 5). This distinction between analogic and digital encoding has provided the starting point for the concept " nonverbal communication", a term which has come into use since the midfifties (cf. Ruesch \& Kees 1970 : 1st edition 1956, for an overview see also Kendon $1981: 2$ ff.), encompassing interdisciplinary research in such fields as communication theory, experimental psychology, biology, social anthropology, animal behavior, and linguistics, especially within the context of semiotic studies. According to Kendon (1981:3)

The term 'nonverbal communication', as it is currently employed, is most frequently used to refer to all the ways in which communication is effected between persons when in each other's presence, by means other than words. It refers to the communicational functioning of bodily activities, gesture, facial expression and orientation, posture and spacing, touch and smell, and of those aspects of utterance that can be considered apart from the referential content of what is said.

Most human social interaction thus involves verbal as well as nonverbal communication (Argyle $1972: 259$ ). We may furthermore hold that it is impossible to sustain a sharp distinction between verbal and nonverbal communication, since according to Lyons (1972:54 f.) there is a complete and intimate interpenetration of non-language and language, where the verbal component can be associated rather with the cognitive and the nonverbal component with the social function.

Conference interpreters seem to have intuitively recognized the above mentioned facts since working in isolation in a sound-proof booth they have insisted in addition to receiving signals through the auditory communication channel - by the transmission of sound through earphones - also on receiving signals through the visual channel. Thus unobstructed view of speaker and audience is an explicit requirement both in the Code Professionel of AIIC (AIIC 1978) and in the ISO Standard pertaining to booths 
for simultaneous interpretation (ISO Standard 2603). These visibility standards are at present re-discussed in the light of experimental studies on remote interpretation as well as the use of TV monitors that are to replace direct view in a conference setting.

But although conference interpreters are known to receive communication signals through different channels - sound and sight - simultaneously, so far only the auditory channel has been given attention in the scientific study of the interpretation process. It seems therefore justified to investigate also the importance of the visual channel in the light of relevant literature on nonverbal or rather nonvocal communication *.

A systematic study of the importance of visual communication signals for conference interpreting was first initiated by the author in 1979 by means of a questionnaire distributed to professional conference interpreters (AIIC) on an international scale. These were analyzed and the results discussed in a paper presented at the 2 nd Congress of the International Association for Semiotic Studies and subsequently made available in a publication (Bühler 1980). This study (henceforth referred to as Study I) was followed up by Study II, a series of interviews with conference interpreters working at UN headquarters in Vienna. The results of this study were presented and discussed at the 1982 Georgetown University Round Table on Languages and Linguistics in a preconference session organised by the Division of Interpretation and Translation of the School of Languages and Linguistics at the above institution (for a summary see Bühler 1982).

In considering methods for the collection of data for such a research project, one has to allow for the fact that nonverbal communication signals are not only less fully subject to conscious control by the sender, since it has been maintained that nonverbal or analogic codifications are more closely related to phylogenetically older modes of codification (Kendon 1981:6), but are norisally also not received or analyzed consciously by the perceiver (Argyle $1972: 257$ ).

And although it can be assumed that interpreters are particularly receptive to all kinds of communication signals including also nonverbal cues (Bühler $1980: 44$ ), the task of consciously accounting for such signals by completing the questionnaires or answering questions in the interviews has proved difficult for many. In fact, nonverbal signals often become apparent only by their absence, e.g. in telephone communication or in remote interpretation, the idea of which is widely rejected by interpreters (cf. Klebnikov 1979). Yet they often find it difficult to give exact reasons why they object to TV monitors replacing direct view, the most frequent objection being a general feeling of discomfort or undue stress (see comments in Study I and Study II). Therefore collecting supplementary data by direct observation in a field situation seems desirable, a method that was used by Bowen in an experimental approach in a classroom mock session, although on a very limited scale only (Bowen 1982).

In order to guarantee objectivity, it is however essential to collect data from a sufficiently large number of informants and to introduce distinguishing parameters in evaluating the results. In Studies I and II the following distinguishing parameters were used : type of conference - regretfully the scientific methods of text-linguistics have as yet not been applied to conference interpretation as they have to written translation (cf. e.g. Bühler 1979); professional status and years of professional experience of interpreters - the receptivity to nonverbal signals is assumed to increase with practice (Buihler $1980: 45$, Argyle 1975:84); sex of interpreters - sex specific differences in receptivity can be assumed (Bühler $1980: 44$, Scherer $1973: 93$ ) ; and linguistic and cultural background of interpreters, since it is widely assumed that the receptivity to nonverbal cues is culture-specific (Bühler 1980 : 45, Argyle 1975: 73 ff., Ruesch \& Kees $1970: 15 \mathrm{ff}$.). 
The main results of evaluating the data obtained in Studies I and II from 62 professional interpreters, 46 of whom had more than ten years of professional experience, can be summed up as follows :

Visual information seems to be important for conference interpreting mainly with regard to

(1) nonvocal signals from sender (= speaker)

(2) nonvocal signals from listener (= delegate)

(3) nonvocal signals in the context of social interaction

(a) among conference participants (conference procedure)

(b) between interpreters and delegates

(c) among interpreters

$a d$ (1) The need for visual information about the sender (= speaker) is generally recognized by interpreters (by $98 \%$ in Study I, cf. Bühler 1980) and even laymen, as it provides additional information about the speaker and helps to understand his words. In view of the clear priority given to the facial expression of the speaker as a means of nonvocal communication, ranked by our informants before hand and finger movements, head movements, direction of gaze, posture, and general appearance (Study I, Bïhler $1980: 46 \mathrm{f}$.), a certain maximum distance between speaker's rostrum and interpreters' booths should not be exceeded. Also the communicative importance of speechconcurrent gestures, undisputed in the literature (cf. e.g. Kendon $1981: 28 \mathrm{ff}$.), was generally emphasized by our informants, such nonvocal signals mostly being felt to support rather than contradict or replace language, the latter case appearing to be language- and culture-specific (Bühler $1980: 47$ f.).

We may therefore conclude that since the most crucial step in the three-phase model (decoding-transfer-encoding) of the translation process (cf. Wilss 1982:80) seems to be the phase of analysis and understanding (cf. also Seleskovitch 1977:11 ff.), the interpreter seems to need as much information as possible for a satisfactory performance, especially in critical situations. Thus Bowen $(1982: 8)$ reports that in her experimental session the interpreter who took relay spent $72 \%$ of her time looking at the speaker, even though she did not understand the language, whereas the person who took directly spent only $481 / 2 \%$ of her time looking. Bowen suggests this interesting finding to be an indication of additional stress, since the interpreter felt she was not getting the full benefit of the floor speech through relay, and we may add here that she probably tried to obtain additional cues for understanding what was said by looking at the speaker.

ad (2) The role played in conference interpreting by nonvocal signals sent by listeners (delegates) has been less readily understood, especially by archtitects planning conference halls, although their importance is generally recognized by the interpreter. Thus in Study I $74 \%$ of the informants claimed it essential for their work to have full view of all the participants in a discussion, while $52 \%$ also wanted to see their audience (Bühler 1980 : 49). In Study II special mention was made of the type of conference, e.g. smaller working groups, where visual cues obtained from the listeners were considered essential.

Here we can assume that one of the phenomena of verbal interaction, that of speaker switching, is of special importance for interpreters, since it often also implies code switching, i.e. the use of a different conference language. Speaker switching or turntaking has been given considerable attention in the study of nonverbal communication (cf. Kendon $1981: 21 \mathrm{ff}$.), where several aspects of bodily movement have been found to function as turn-taking cues, prominent among them changes in gaze direction (cf. Kendon $1981: 22$, Beattie $1981: 297$ ff.) and turn-initiation cues have been differen- 
tiated from turn-termination cues (cf. DeLong $1981: 251 \mathrm{ff}$.). In order to avoid being surprised by unexpected code switching, interpreters seem to be particularly tuned to so-called speech-preparatory movements (cf. also Scherer $1973: 88$ ). Thus mention was made by interviewees in Study II of the fact that they 'usually could guess who was going to speak' or that they observed the speaker 'getting ready in little ways'. On the other hand, if must be assumed that in working groups that use interpretation floor apportionment is to a certain extent ritualized, e.g. by raising of hands or recognizing a speaker by the chairman, the latter being effected by verbal invitation or by nonverbal signalling. In this case the interpreter will again have to rely exclusively on visual information in order to prepare for speaker switching before he hears a different voice in another language over the earphones. Conference interpreters are thus receptive for and depend on nonverbal turntaking cues, but they of course also expect full view of a discussion partner that has in his turn become a speaker. It seems that such visual information is often lacking or only provided with an undue time lag when TV monitors replace direct view (according to comments in Studies I and II).

In addition, as has been mentioned before, interpreters in certain working situations also require visual feedback from their listeners. According to Argyle (1972: 255) when someone is speaking he needs intermittent, but regular, feedback on how others are responding, so that he can modify his utterance accordingly, he needs to know whether his listeners understand, believe or disbelieve, are surprised or bored... This information is usually obtained by intermittent visual scanning of the other's face, although most people are not consciously aware that they are receiving this information (Argyle 1972: 258). Since the interpreter cooperates with his listener to make sure he understands (Seleskovitch $1978: 113$ ), - a fact that was also frequently pointed out in Study II where the importance of a negative feedback was stressed, more than half of the informants in Study I wanted to see the reactions of their audience (Bühler 1980: 49), either for reasons stated above or perhaps also for reasons mentioned under ( $3 \mathrm{~b}$ ) below. As a consequence, off-situations where the interpreter cannot see his 'clients' at all or, for certain working situations, booths from where he cannot scan their faces for nonvocal cues are generally felt to be undesirable.

ad (3) The importance of nonvocal signals for interpreters in the context of social interaction was generally recognized by informants in Study I as well as in Study II, although in analyzing these comments we again encounter the phenomenon that our informants at times found it an extremely difficult task to account consciously by differentiation and verbal labelling for such visual communication signals that are often not deliberate, but unintentional ; - a finding which does not surprise us in view of the fact that the problem of notation and verbal labelling has remained essentially unsolved in the study of nonverbal communication even in the face of a number of solutions proposed (cf. Scherer $1973: 99$ ff., Argyle $1975: 57$, Kendon $1981: 14$ ff.). Furthermore the distinguishing parameters of sex, cultural and linguistic background and years of professional experience of the interpreter as introduced in our studies will have to be supplemented to produce a personality profile of each informant for more extensive evaluation. It is therefore suggested to continue and expand the study of the phenomena to be discussed under (3) on an interdisciplinary level.

ad (3a) As regards social interaction among conference participants, $84 \%$ of informants in Study I wanted visual information as it expressed interpersonal attitudes of speakers, audience and discussion partners, while in Study II mention was made of the need to 'get the feel' or the 'atmosphere' of a meeting by way of the visual channel. The same percentage of informants in Study I also wanted visual information about the general conference procedure and conference ritual. In Study II very general comments 
like 'we need to see everything' or 'as much as possible' corroborate the above mentioned difficulties in differentiation, while one interviewee reporting that he sometimes gets up from his chair to have an overview of the whole conference setting 'at one glance' thus underlines the well-known time-saving factor of analogic encoding as compared to digital encoding. We can therefore assume that visual information provided by TV monitors, which at best can only scan sections of the conference hall, will be considered insufficient by many interpreters also with regard to social interaction.

ad (3b) An unexpected but interesting outcome of Study II was the fact that a number of interpreters insisted on the importance of a two-way visual communication between interpreter and delegate and several examples were given. The need for privacy at work (as for instance provided by tinted glass windows for booths) obviously depends on the personality profile of the interpreter, but from comments received from our informants it seems clear that most interpreters do not want 'to work in a vacuum' (comment in Study II), that they want to know whether someone is listening to them and in some cases also want to be seen or known by the delegates for whom they work and to receive visual feedback. Even within the narrow scope of this study we can assume that most interpreters resent being regarded as 'mere translation machines' (comment in Study II) and that lack of participation produces demotivation, thus increasing stress and reducing the quality of performance.

ad (3c) Not unexpectedly visibility between booths was unanimously claimed by interviewees in Study II to be very essential for various reasons, such as the exchange of information on documents or terminology (here again the above-mentioned time-saving factor comes into play), as well as to provide the feeling of not being isolated or of knowing what is happening in other booths. Surprisingly this fact seems to be frequently overlooked, since visibility between booths was reported by informants to be often poor, obstructed or even absent.

In conclusion we might state that the empirical data collected and analyzed in Studies I and II, supported by literature on the nature and importance of nonvocal signals for communication, prove that any impairment of the natural multichannel communication situation is highly undesirable also in conference interpreting. Or, as one informant put it : 'Vision helps and adds to the interest'.

\footnotetext{
* Some aspects of utterance pertaining to nonverbal communication are often subsumed loosely under the heading of 'paralinguistic phenomena', such as, for instance, voice quality, pitch, loudness, timing, and 'prosodic features' including intonation and stress, as well as other nonverbal vocal signals such as coughing and laughing (cf. Lyons $1972: 52$ f., Scherer $1973: 6 \mathrm{ff}$.). Such signals, which might warrant a separate study, will be excluded from our present investigation, which will therefore concentrate on the nonvocal rather than the non-verbal signals received by the interpreter.
}

\section{REFERENCES}

AICC (1978) : Code Professionnel, Association internationale des interprètes de conférence, Genève. ARGYLE; M. (1972) : "Non-Verbal Communication in Human Social Interaction', in R. Hinde (ed.), pp. 243-269.

ARGYLE, M. (1975) : Bodily Communication, London.

BEATTIE, G. (1981) : "Sequential Temporal Patterns of Speech and Gaze in Dialogue", in A. Kendon (ed.), pp. 297-321.

BOWEN, M. (1982) : Summary in Report on the Georgetown University Round Table, Interpretation and Nonverbal Communication, National Resource Center for Translation and Interpretation, Georgetown University, Washington, D.C., State University of New York, Binghamton, N.Y., pp. 7-8.

BÜHLER, H. (1979) : "Suprasentential Semantics and Translation", in Meta, vol. 24, no 4, pp. 451.458.

BÜHLER, H. (1980) : "Translation und nonverbal Kommunikation", in W. Wills (ed.), Semiotik und Übersetzen, Tübingen, pp. 44-52. 
BÜHLER, H. (1982) : Summary in Report on the Georgetown University Round Table, Interpretation and Nonverbal Communication, National Resource Center for Translation and Interpretation, Georgetown University, Washington, D.C., State University of New York, Binghamton, N.Y., pp. 1-3.

DE LONG, A. (1981) : "Kinesic Signals at Utterance Boundaries in Preschool Children", in A. Kendon (ed.), pp. 251-283.

HINDE, R. (ed.) (1972) : Non-Verbal Communication, London-New York-Melbourne.

ISO Standard 2603 : Booths for Simultaneous Interpretation.

KENDON, A. (1981) : "Introduction : Current Issues in the Study of 'Nonverbal Communication", in Kendon (ed.), pp. 1-57.

KENDON, A. (ed.) (1981) : Nonverbal Communication, Interaction, and Gesture, The Hague-Paris-New York.

KLEBNIKOV, G. (1979) : "Remote Interpretation Experiment", in AIIC Bulletin VII/2, pp. 169-175.

LYONS, J. (1972) : "Human Language", in R. Hinde (ed.), pp. 49-86.

RUESCH, J. \& W. KEES (1970) : Nonverbal Communication, Notes on the Visual Perception of Human Relations, Berkeley-Los Angeles-London.

SCHERER, K. (1973) : Nonverbal Kommunikation, Hamburg.

SELESKOVITCH, D. (1978) : Interpreting for International Conferences, Problems of Language and Communication, Washington.

WILSS, W. (1980): The Science of Translation, Problems and Methods, Tübingen. 